\title{
Editorial
}

\section{VERT: herramienta de educación virtual en física médica}

\author{
Jorge Homero Wilches-Visbal ${ }^{1}$
}

1Universidad del Magdalena, Santa Marta-Colombia, jwilches@unimagdalena.edu.co

https://doi.org/10.22430/22565337.2216

La conformación de equipos interdisciplinares se ha asociado con mejores resultados en la prestación de servicios de salud porque en ellos confluyen las distintas habilidades intelectuales y destrezas prácticas de cada integrante. En radioterapia, el trabajo conjunto de físicos médicos y médicos radioterapeutas es esencial en la gestión y planificación del tratamiento, por lo que cada uno debe entender el rol que cumple el otro dentro del proceso [1].

El físico médico es el profesional encargado de garantizar la aplicación eficaz de la dosis de radiación, que permita la consecución del mejor resultado diagnóstico o terapéutico posible para el paciente y con el menor daño posible para el personal ocupacionalmente expuesto y para el público. Por lo tanto, normalmente se exige que tenga un pregrado en física o ingenierías afines, posgrado en física médica y un periodo de entrenamiento clínico en radiodiagnóstico, medicina nuclear y/o radioterapia [2].

La utilización de herramientas virtuales para el aprendizaje crece aceleradamente en todas las áreas de la salud y las ciencias, incluida la física médica. En ese sentido, VERT (en inglés, Virtual Environment for Radiotherapy Training), diseñado en el Reino Unido en 2009, ofrece a estudiantes de física médica la oportunidad de adquirir habilidades y conocimientos realizando actividades repetitivas en un ambiente interactivo y libre de riesgos para el paciente o los equipos. VERT reproduce el entorno físico de una sala de radioterapia: acelerador lineal, el hand pedant, gráfico del haz de radiación, datos de planificación, sistema de cargue de imágenes tomográficas y DICOM (en inglés, Digital Imaging and Communication in Medicine). Además, permite simular la distribución de dosis y medidas de calibración, con opción de introducir errores de posicionamiento del paciente [3]-[5].

Aunque los estudios son limitados, en Reino Unido y Australia se han reportado beneficios por el uso de VERT relacionados con un mejor manejo de conceptos fundamentales de física de la radioterapia, anatomía, diseño de administración de dosis y mayor confianza, así como un instrumento valioso que coadyuve a los métodos de enseñanza tradicional de estudiantes de física médica [3].

Adicionalmente, se ha visto que utilizar VERT en la educación de pacientes sometidos a radioterapia disminuye la ansiedad e incrementa el empoderamiento durante el proceso de tratamiento, al proporcionarles información adecuada para el consentimiento, resolver sus inquietudes y prepararlos para cada una de las etapas [5].

En Colombia, ninguna de las dos IES que ofrecen el programa de maestría en física médica (Pontificia Universidad Javeriana y Universidad Nacional de Colombia) reporta la utilización de VERT como entorno de entrenamiento antes del inicio de las prácticas hospitalarias, a pesar de sus bondades e incorporación en planes de estudios en otros países y en hospitales 
de reconocida trayectoria como el Mayo Clinic, MD Anderson Texas o el Hospital do Câncer de Barretos en Brasil [6].

Sea el tiempo de pandemia, que corroboró la importancia de la educación virtual en todas las esferas del conocimiento, la ocasión propicia para que docentes, universidades y centros de radioterapia evalúen la posibilidad de incorporar VERT en los planes de estudios posgraduales y/o de entrenamiento clínico en física médica, así como instrumento educativo en pacientes sometidos a tratamiento.

\section{REFERENCIAS}

[1] Y. A. Jimenez; D. I. Thwaites; P. Juneja; S. J. Lewis, "Interprofessional education: evaluation of a radiation therapy and medical physics student simulation workshop", J. Med. Radiat. Sci., vol. 65, no. 2, pp. 106113, Jun. 2018. https://doi.org/10.1002/jmrs.256

[2] I. Czaplinski; A. L. Fielding, "Developing a contextualised blended learning framework to enhance medical physics student learning and engagement”, Phys. Medica, vol. 72, pp. 22-29, Apr. 2020. https://doi.org/10.1016/j.ejmp.2020.03.010

[3] Y. A. Jimenez; C. R. Hansen; P. Juneja; D. I. Thwaites, "Successful implementation of Virtual Environment for Radiotherapy Training (VERT) in Medical Physics education: The University of Sydney's initial experience and recommendations", Australas. Phys. Eng. Sci. Med., vol. 40, no. 4, pp. 909-916, Dic. 2017. https://doi.org/10.1007/s13246-017-0592-9

[4] Scienty Med, "VERT - Simulador virtual de LINACS", YouTube, 2021. URL

[5] Y. A. Jimenez; S. Cumming; W. Wang; K. Stuart; D. I. Thwaites; S. J. Lewis, "Patient education using virtual reality increases knowledge and positive experience for breast cancer patients undergoing radiation therapy", Support. Care Cancer, vol. 26, no. 8, pp. 2879-2888, Ago. 2018. https://doi.org/10.1007/s00520018-4114-4

[6] Vertual, «VERT - Installations», 2021. URL 